Original Research Paper

\title{
Numerical Study of the Behavior of Single-Sided Protruding Slabs
}

\author{
Reza Salehi and Abbas Akbarpour Nikghalb Rashti
}

Islamic Azad University, South Branch, Tehran, Iran

\author{
Article history \\ Received: 01-04-2018 \\ Revised: $10-04-2018$ \\ Accepted: 04-05-2018 \\ Corresponding Author: \\ Reza Salehi \\ Islamic Azad university, South \\ Branch, Tehran, Iran \\ Email: salehi.reza14@yahoo.com
}

\begin{abstract}
Due to the high seismicity of our regions, engineers have always sought to provide various solutions to improve the performance of buildings and consequences control of powerful earthquakes. Building Lighting is one of the methods used to reduce earthquake forces. The use of prefabricated slabs is one of the ways to reduce the dead load of a building. In this study, four types of prefabricated slabs with different thicknesses under a certain dead load have been modeled in ABAQUS Software. By analyzing nonlinear static analysis, slab capacity and nonlinear behavior are evaluated. The results show that by increasing the thickness of the slab, the shear strength of the slab increases. The results also show that the ultimate strength has been reduced in a hollow slab with polygon holes (non-circular).
\end{abstract}

Keywords: Prefabricated Slabs, Hollow Slab, ABAQUS Software, Nonlinear Static Analysis

\section{Introduction}

Hollow-Core Slabs are one of the common types of ceilings used in the prefabricated buildings industry, which are calculated and constructed based on gravity loads (Sgambi et al., 2014). These components are manufactured in a hall equipped with computer control systems. The advantages of these ceilings include removing the joists, blocks, fire resistance and thermal insulation, removing the pile, molding and pile, moisture resistance, fire and corrosion, reducing the effective thickness of the ceiling, reducing the total building weight, reducing the consumption of concrete, fittings and reduced manpower, as well as reduced production costs (Pisanty and Regan, 1991; CEN, 2011). Hollow slabs can be produced with specific length and width (length 4 to $25 \mathrm{~m}$ ) and different thicknesses in the factory (FIB, 2012). In order to reduce the dead load in the longitudinal section, each piece of these ceilings typically has between 4 and 6 holes, which extend throughout the length of the hollow slab (FIB, 2012). Pantyhose slabs are widely known around the world as efficient and cost-effective systems. Jane et al. (CEN 2011) argued that in the longitudinal section of the sloping slabs, successive cavities (as reduce slab weight) could reduce the cost of constructing and passing mechanical and electrical installations. The method of suspending ceilings is usually such that, after placing the ceiling on the beam (metal, prefabricated, or in-situ beam), the double-sided roof hooks that are involved with the beam's projections are fitted with suitable longitudinal reinforcements. The rebar extends through two adjacent ceilings which are perpendicular to the above-mentioned longitudinal reinforcement to the outer edge of the beams and then form the outer surface of the beams and finally concretes (ACI, 2005). For the first time, a person named John Mill, founded the prefabricated products company Mill in 1989. In 1905, he (Hegger et al., 2009) was able to produce the first prestressed products. The third generation of the family of the Mails managed to bring new achievements during their presence in the company, one of which was the creation of the Hallucore ceilings. Dimitrios et al. (2013) did some practical works for construction of building to focuse more in the details of ceilings to make them lighter, so the prestressed building design start to helped to the industry. In Iran, several companies, including Disman and South Kish, have been mentioned. In projects such as Mika residential and commercial towers with a total area of 13,000 square meters in Qeshm, Mobin mono-facade in an office tower project with a total area of 5000 square meters in the city of Mashhad, they used pre-fabricated ceiling 
slabs. Hegger et al. (2009), following experiments with advanced equipment, concluded that by increasing the thickness of the concrete on the slab, the height of the section increased, as a result, the shear strength increased and it showed reduction in the deformation of the ceiling of the hollow slab. In areas where housing shortages and demand are high, one solution is to increase production and reduce production time. For this reason, prefabricated products can be used. An example of these products is the hallo-work prestressed ceiling. Due to the fact that this technology is not common in Iran and many construction contractors are not familiar with the advantages of light ceilings and use common ceilings such as jointed blocks, juniper cores, more research is needed in this regard. Moreover, Fallahi et al. (2018) did numerical study on the behavior of RC elements to evaluate shear and stiffness behavior with concrete which used different methods of nonlinear analysis.

\section{Modeling}

In this study, four models of protruding hollow slabs were modeled on the basis of the Brunesi and Nascimbene (2015) did some works using ABAQUS, a finite element software. Figure 1 shows the damping slabs in the modeling.
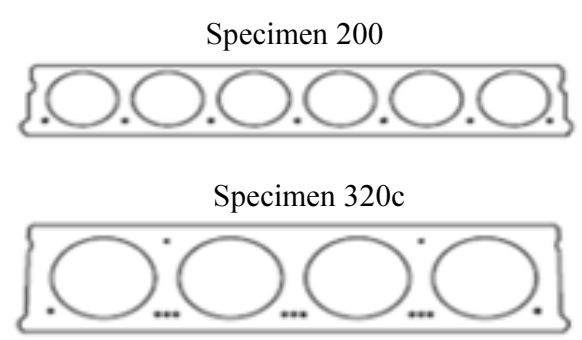

Figure 2 shows examples of the implementation of the hollow slab and Table 1 shows the characteristics of the slabs of interest.

The concrete parts have been modeled as solid elements and the cut-extrusion method is used to create holes. Moreover, concrete damage plasticity model is used to define concrete behavior. In this research, the theoretical method by Soleimani and Roudsari (2015; Sayyar Roudsari et al., 2018; Roudsari et al., 2018) has been used. Because, he evaluated CDP model very clearly with MATLAB toolbox and validate with several concrete models with various loading conditions and type of structures.

Figure 3 shows the cross-section of the model slabs in the ABAQUS software and Fig. 4 shows the S200 slab in the software.

As shown in Fig. 1, the rebar diameter used in the slab is $125 \mathrm{~mm}$. The mesh used in the model are prestressed, with a force equal to $11,000 \mathrm{~kg} / \mathrm{cm}^{2}$ (Brunesi and Nascimbene, 2015). All rebars which are used in their tensile area and only in the S320c model, in addition to the tensile bars, compression bars are also used. The compressive strength of concrete is 32.50 MPa (Brunesi and Nascimbene, 2015). The static loading is applied surface to $100 \mathrm{~N} / \mathrm{cm}^{3}$ on certain slab surfaces. The load is statically incremental and according to Fig. 5, four bars are applied to the slabs.

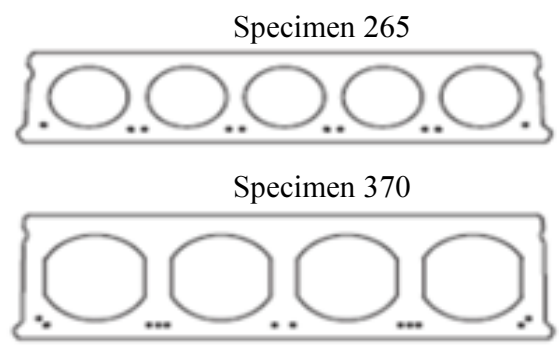

Fig. 1: The speculative slabs for modeling this research (Brunesi and Nascimbene, 2015)

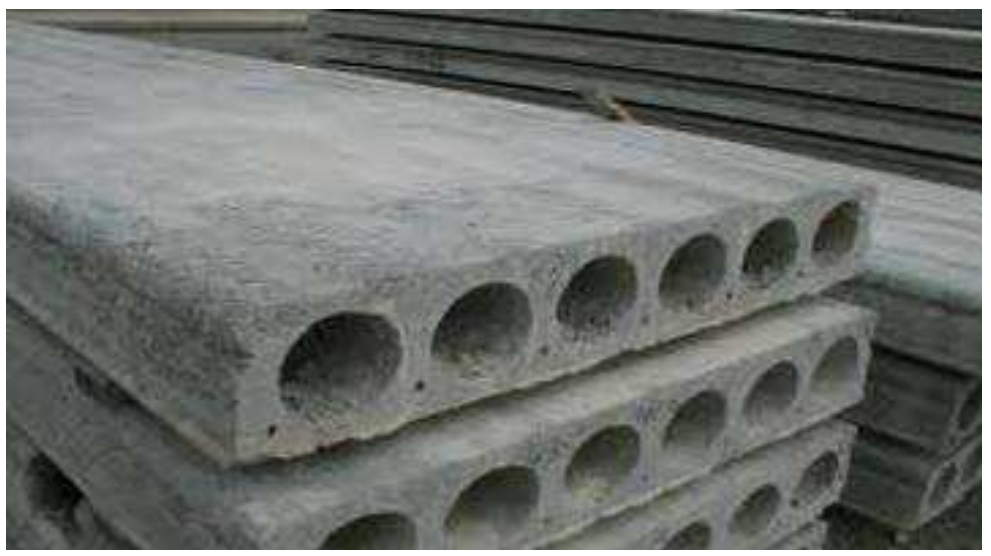

Fig. 2: Examples of the implementation of the slabs intended for construction (Brunesi and Nascimbene, 2015) 
Reza Salehi and Abbas Akbarpour Nikghalb Rashti / American Journal of Engineering and Applied Sciences 2018, 11 (2): 643.651 DOI: 10.3844/ajeassp.2018.643.651
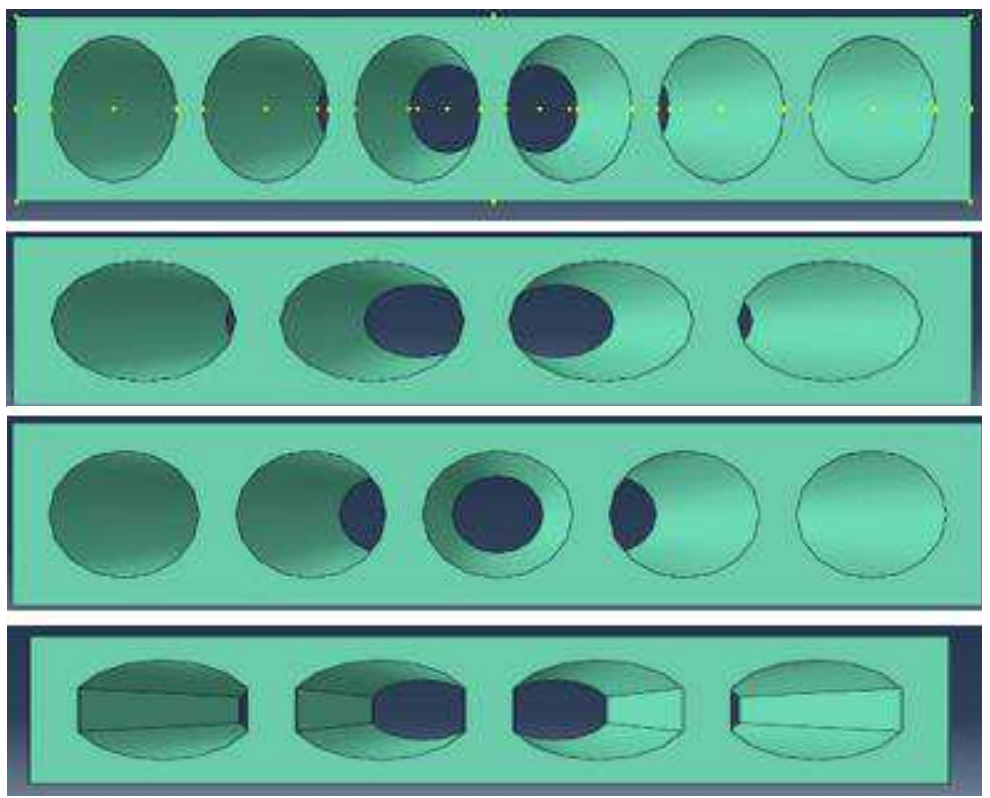

Fig. 3: Models created in ABAQUS software

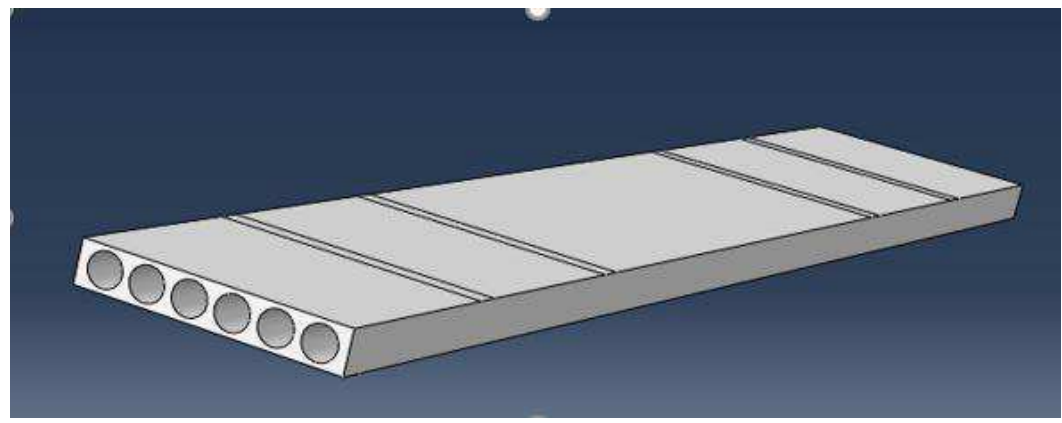

Fig. 4: Hollow slab created in ABAQUS software

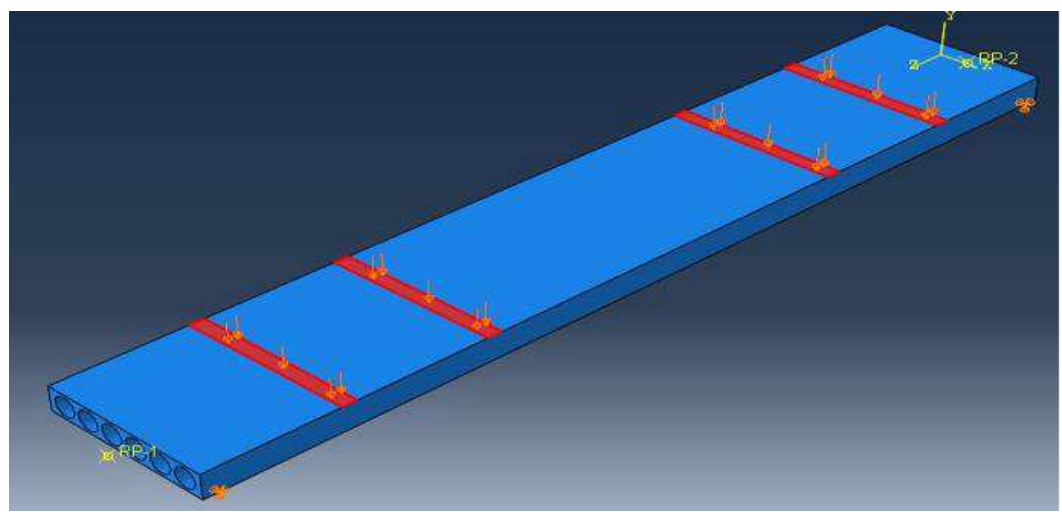

Fig. 5: Loading pattern in the desired field in this research

Table 1: Characteristics of the damn signs in modeling this research (Brunesi and Nascimbene, 2015)

\begin{tabular}{|c|c|c|c|c|c|}
\hline Slab type & Cavity shape & Slab length $(\mathrm{mm})$ & Slab thickness $(\mathrm{mm})$ & John Deal Thickness & Slab thickness below the cavities \\
\hline$\overline{\text { S200 }}$ & circular & 6603 & 200 & 239 & 19 \\
\hline S265 & circular & 5213 & 260 & 228 & 42 \\
\hline S320c & circular & 5945 & 310 & 263 & 40 \\
\hline S370 & Non-circular & 6942 & 359 & 272 & 54 \\
\hline
\end{tabular}




\section{Presentation of Results}

In this section, the results of static nonlinear static analysis are presented.

\section{Model S200}

The static loading chart for the S200 model is shown in Fig. 6. According to this form, the deflection at the center of the slab is $2.05 \mathrm{~cm}$ at the end of the linear behavior and in the range of 2.05 to 2.58 , the linear region becomes a nonlinear region and extends from the area of 2.58 to the material of the area nonlinear. Figure 6 also shows that the shear strength of this slab is $407.69 \mathrm{KN}$ with a final displacement of 5.79.

\section{Model S265}

The loading chart of the S265 model is shown in Fig. 7. According to the results obtained that the nonlinear behavioral begins in the deflection at the center of slab at 2.21 centimeters and the slab behavior in deflection with a range of 2.21 to $2.36 \mathrm{~cm}$, the linear region becomes a nonlinear region and ranges from 2.36 centimeter. In greater lengths, slab has entered a non-linear region. The shear strength of this slab is $808.10 \mathrm{KN}$ with a final displacement of 5.82.

\section{Model S320C}

The loading chart of the S320C model is shown in Fig. 8. As the slab load has been incrementally increased, the deflection at the center of slab gradually increased. According to the results, a $2.10 \mathrm{~cm}$ shows the linear behavior of the end and in the range of 2.10-2.23, the linear region becomes a nonlinear region. From point 2.23 , the he incident area of slab got nonlinear. The shear strength of this slab is $1572.26 \mathrm{KN}$ with a final displacement of 5.93 .

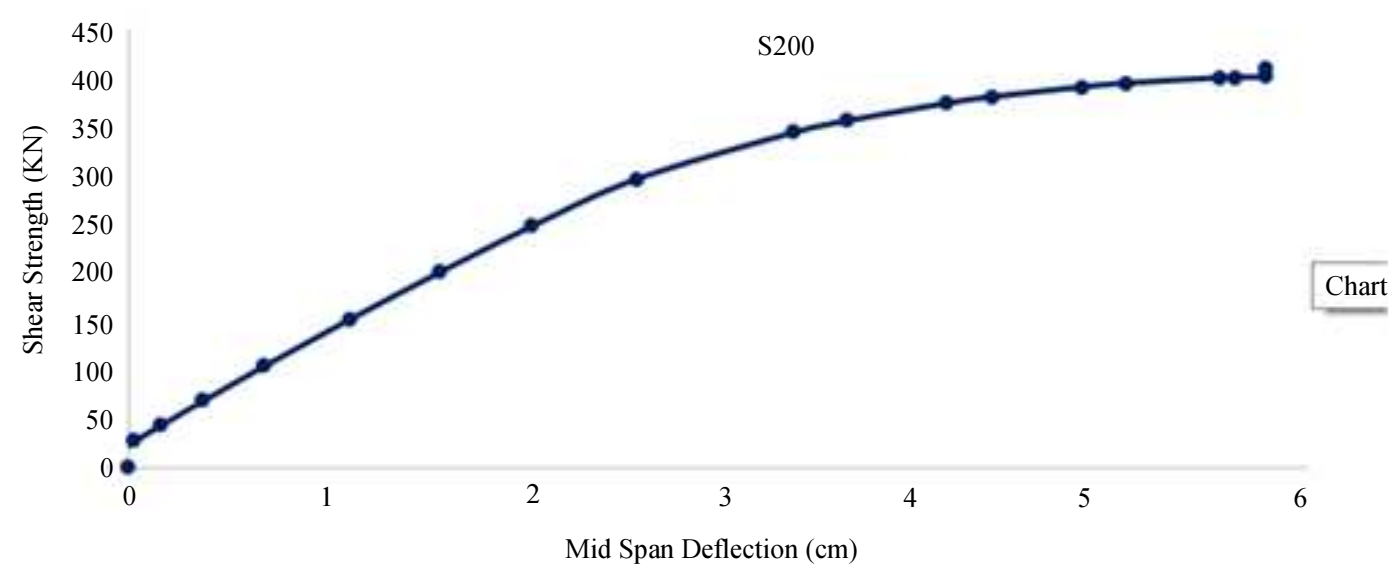

Fig. 6: Nonlinear static loading diagram of the S200 model

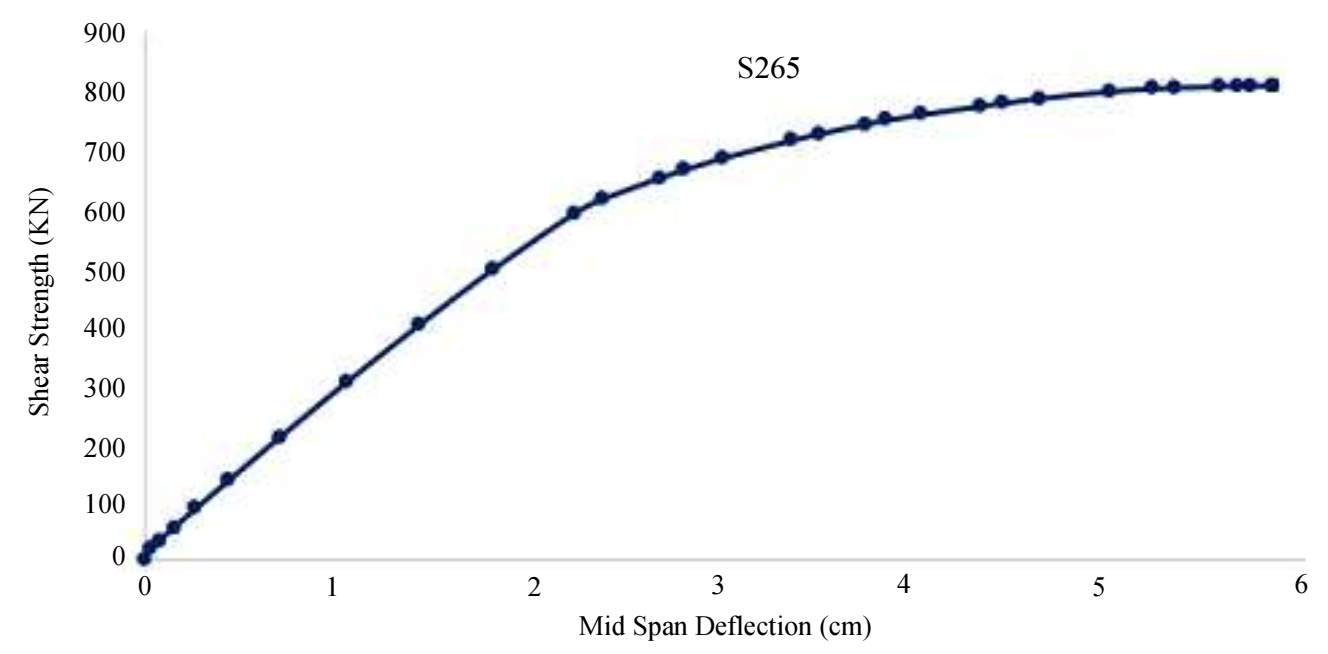

Fig. 7: Stochastic nonlinear static loading chart for the S265 model 


\section{Model S370}

The loading chart of the S370 is shown in Fig. 9. According to the results, for the deflection of the middle of the span $1.50 \mathrm{~cm}$, the slab is located at the threshold of nonlinear behavior. The linear region becomes a non-linear region at the range of 1.50 to $1.90 \mathrm{~cm}$ and the nonlinear area is more than $1.90 \mathrm{~cm}$. The shear strength of this slab is $1502.73 \mathrm{kN}$, with a final displacement of 3.97 .

The loading chart of all four models is shown in Fig. 10 for a better comparison. As you can see, the S320 has more elastic stiffness than other models. The S200 is less elastic hardness than other models.
The numerical values of force and displacement of each of the four models under incremental loading are shown in Table 2. Which shows that with increasing thickness, the maximum displacement in the linear range is reduced, but the amount of force increases with thickness and the thickness of each one is increased, the value of the strength of hollow slab is increased.

With a compressive strength of $32.3 \mathrm{MPa}$, the tensile strength is about $10 \%$, equivalent to $3.23 \mathrm{MPa}$. Therefore, tensile stress tensile strengths of 32.5 and tensile stress constants of -325 are regulated. The dark areas that indicate concrete stiffness indicate a tensile deficiency at a tight pressure. Figures 11 to 18 show the distribution of tensile stresses in the slab at the end of loading.

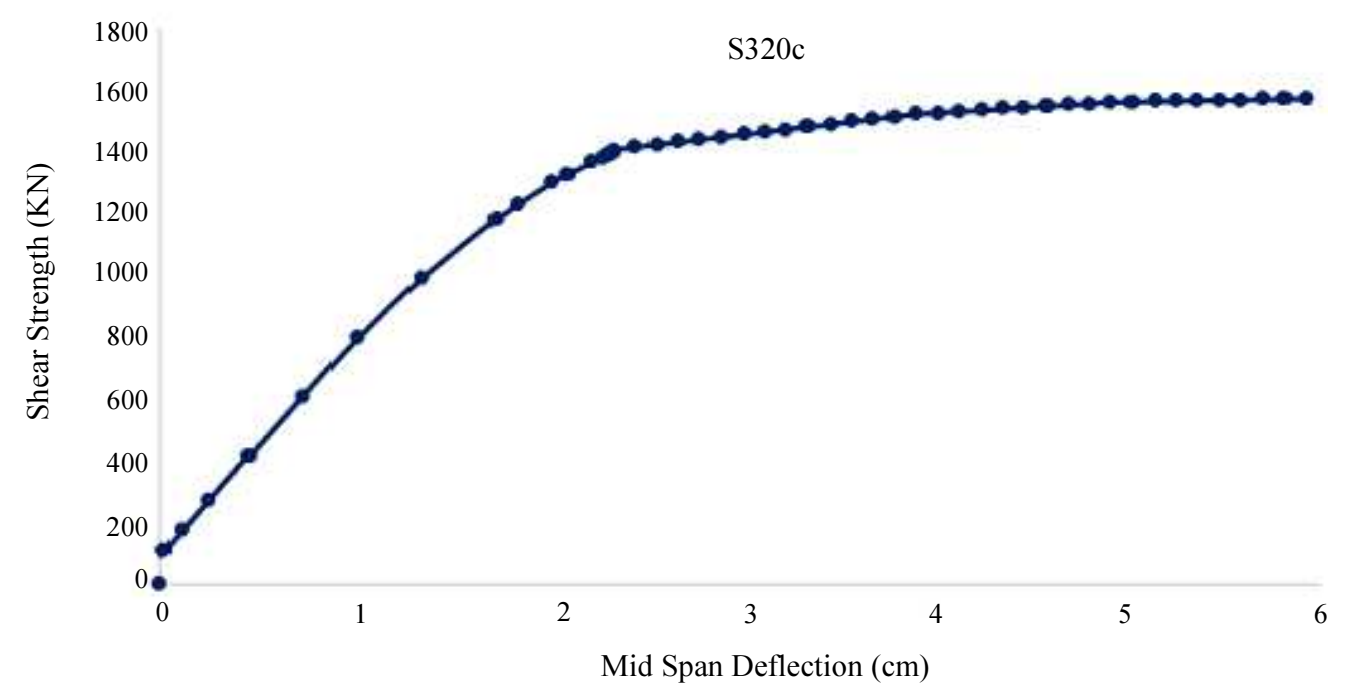

Fig. 8: Nonlinear static loading graph of the S320C model

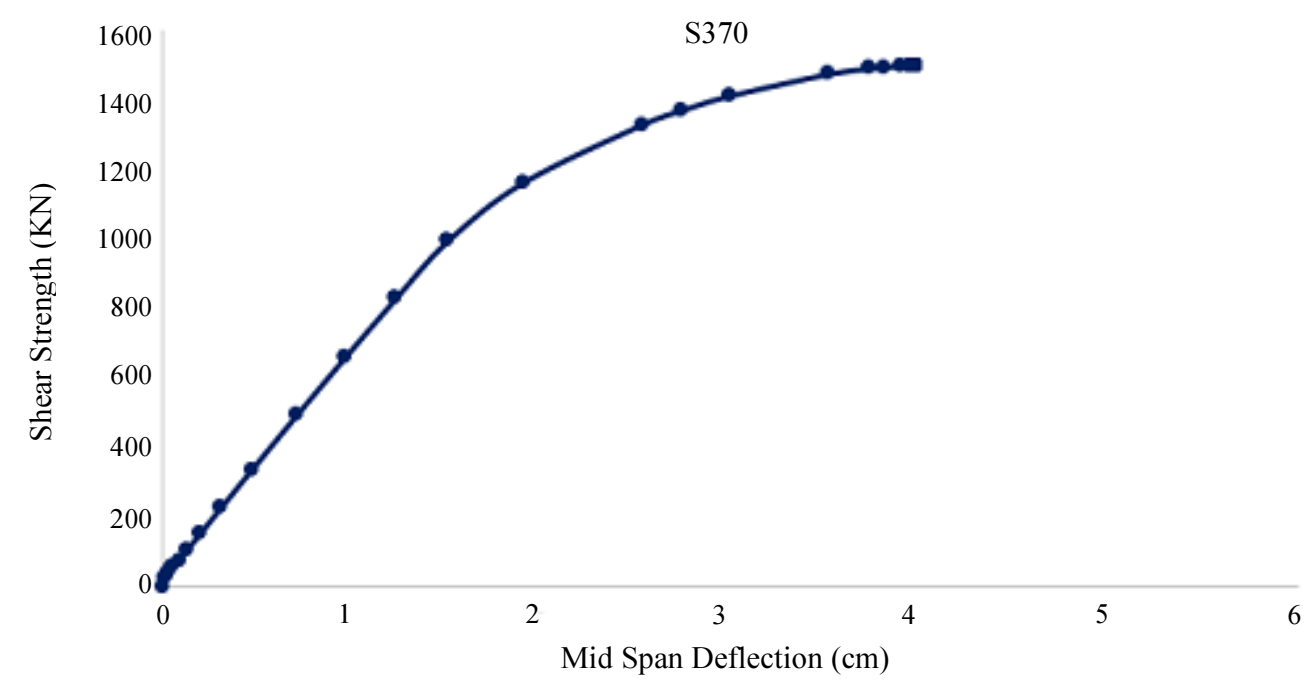

Fig. 9: Nonlinear static loading diagram of the S370 
Reza Salehi and Abbas Akbarpour Nikghalb Rashti / American Journal of Engineering and Applied Sciences 2018, 11 (2): 643.651 DOI: 10.3844/ajeassp.2018.643.651

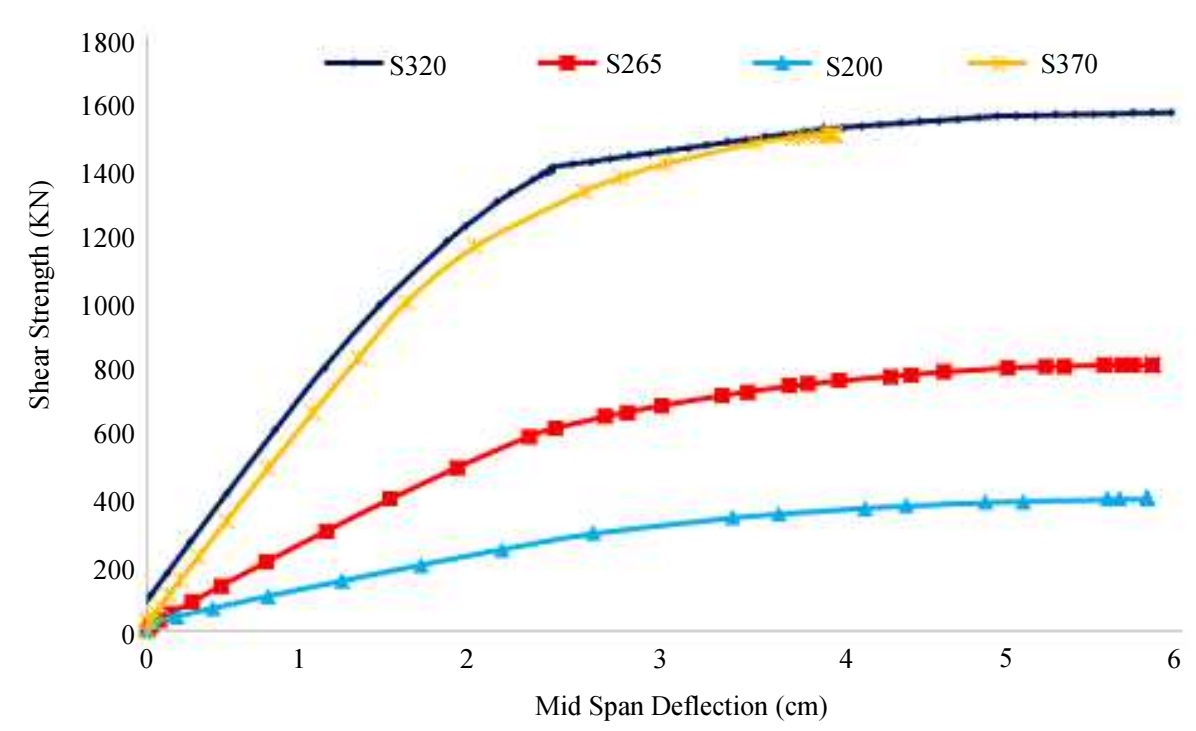

Fig. 10: Load capacity of 4 models

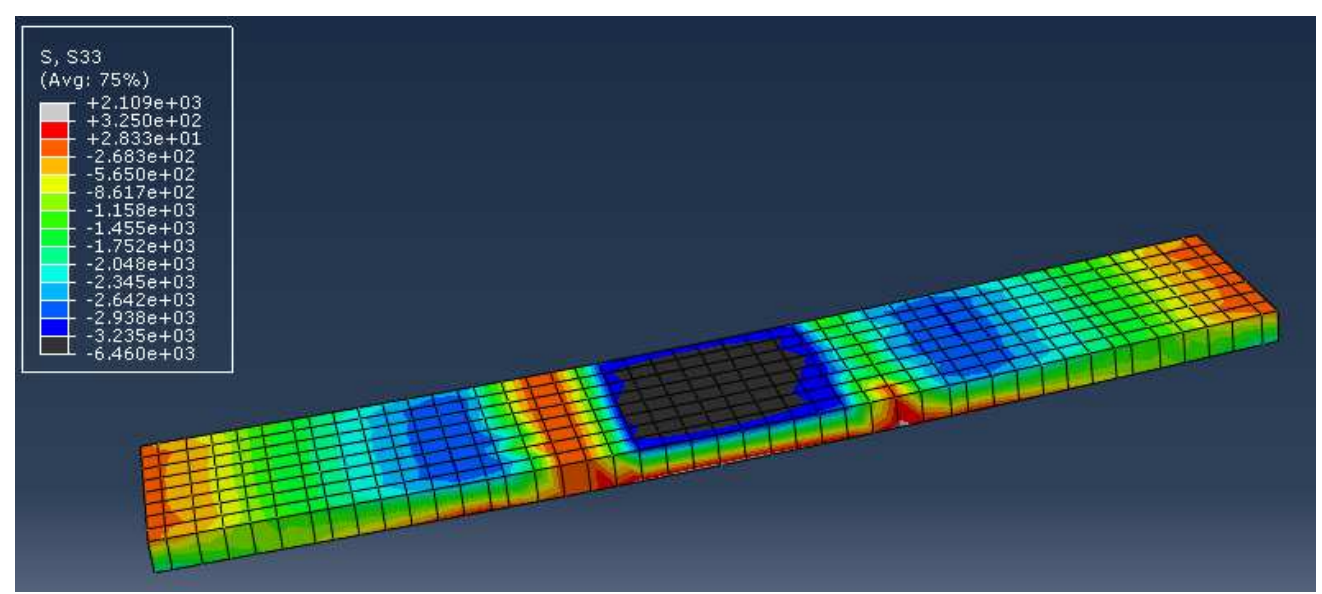

Fig. 11: Normal compression stress on concrete in the S200 at the end of loading

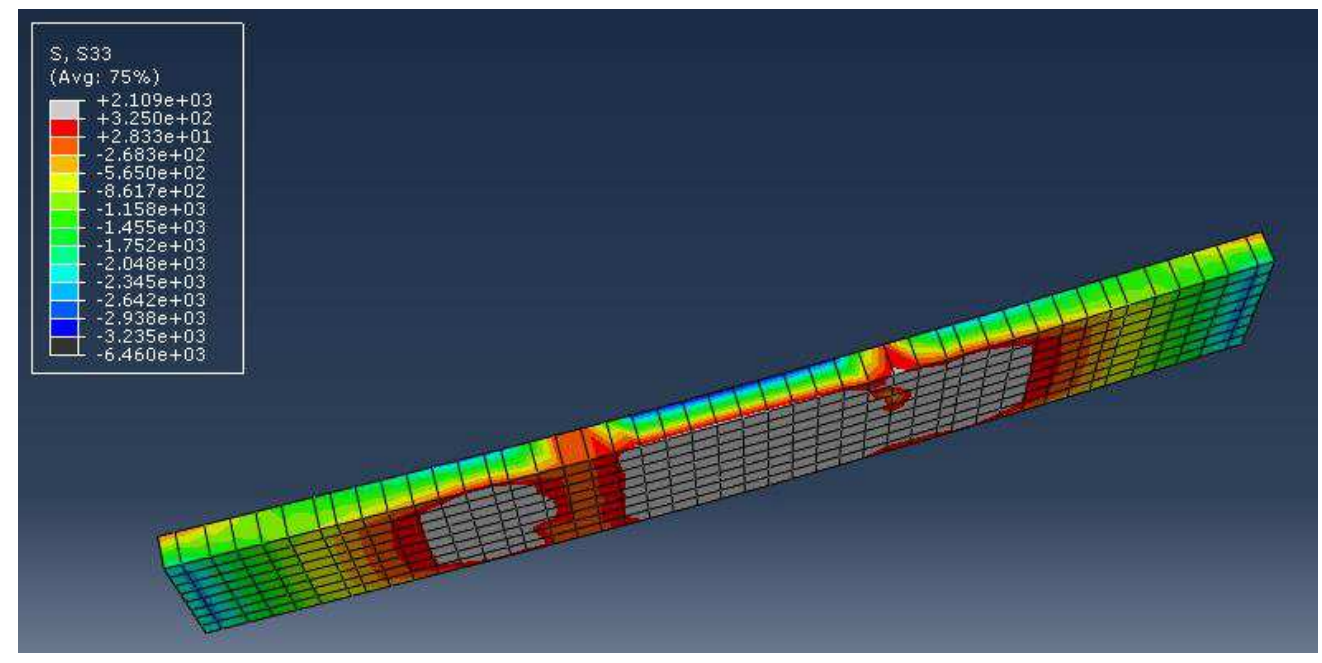

Fig. 12: Normal tension stress in concrete in the S200 at the end of loading 
Reza Salehi and Abbas Akbarpour Nikghalb Rashti / American Journal of Engineering and Applied Sciences 2018, 11 (2): 643.651 DOI: 10.3844/ajeassp.2018.643.651

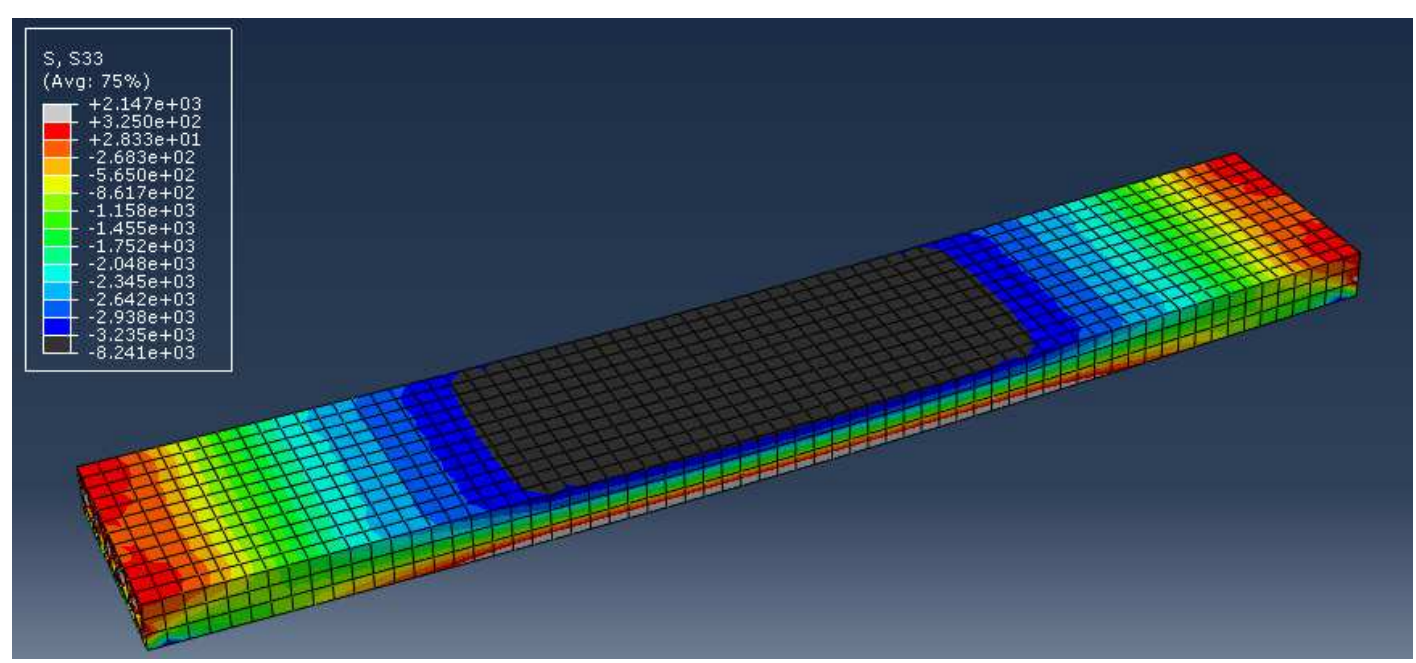

Fig. 13: Normal compression stress on concrete in the S265 at the end of loading

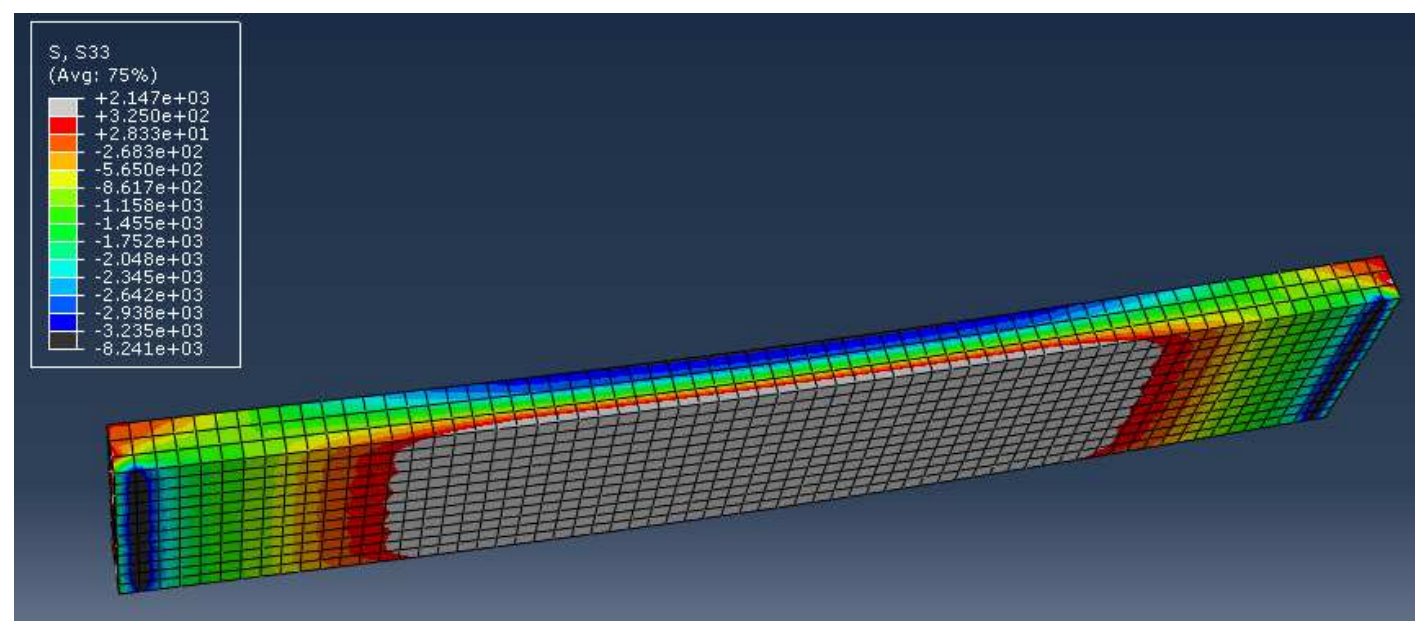

Fig. 14: Normal tension stress in concrete in the S265 model at the end of loading

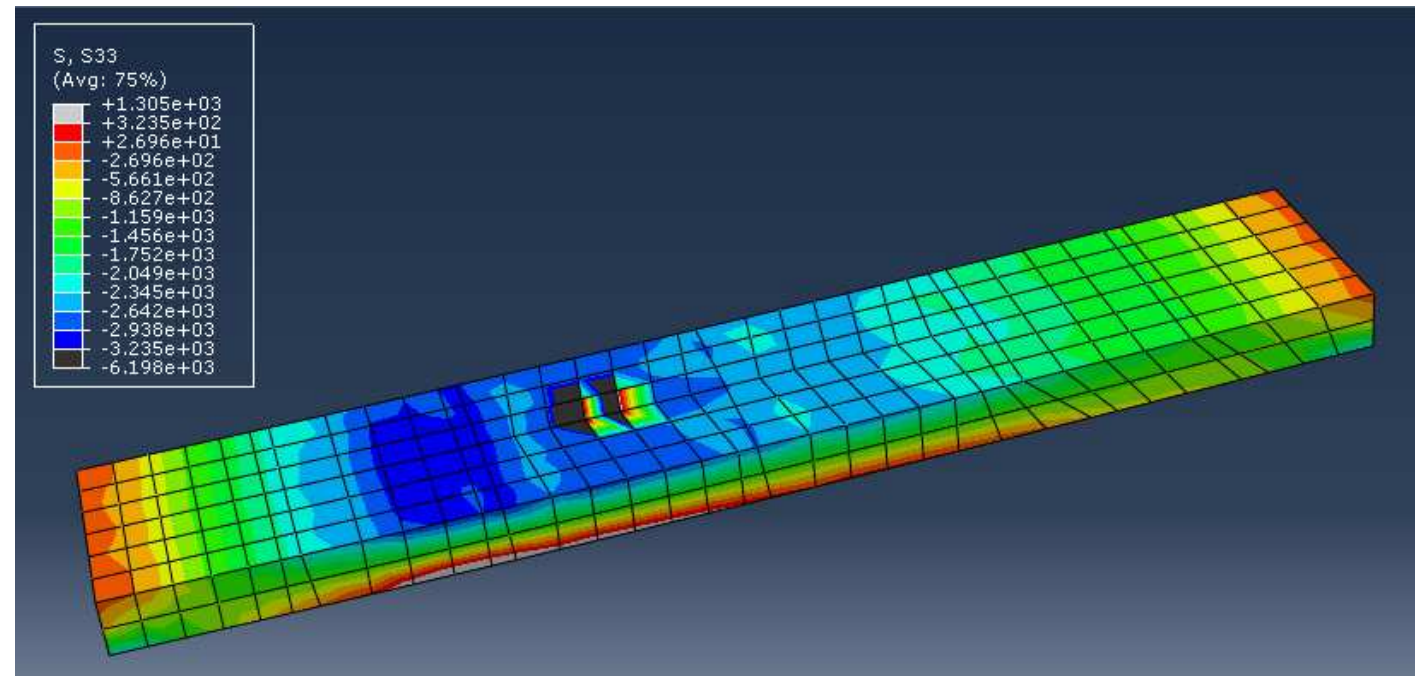

Fig. 15: Normal compression stress on concrete in the S320C at the end of loading 
Reza Salehi and Abbas Akbarpour Nikghalb Rashti / American Journal of Engineering and Applied Sciences 2018, 11 (2): 643.651 DOI: 10.3844/ajeassp.2018.643.651

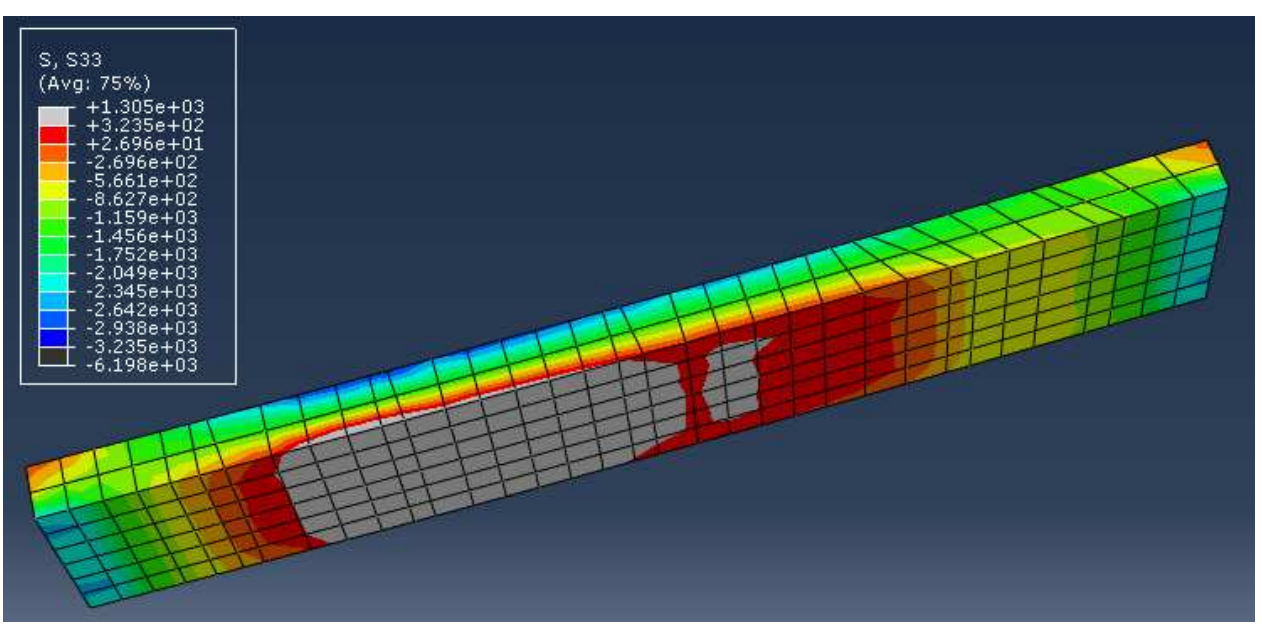

Fig. 16: Normal tensile strength of concrete in the S320C model at the end of loading

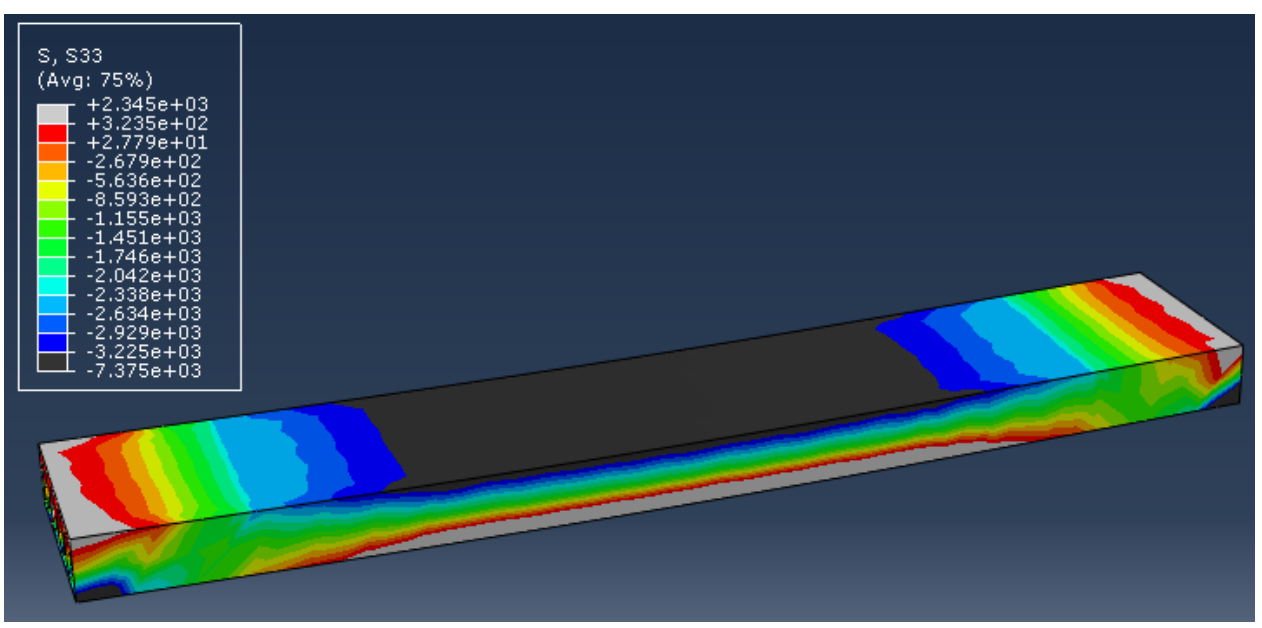

Fig. 17: Normal compression stress on concrete in the $S 370$ at the end of loading

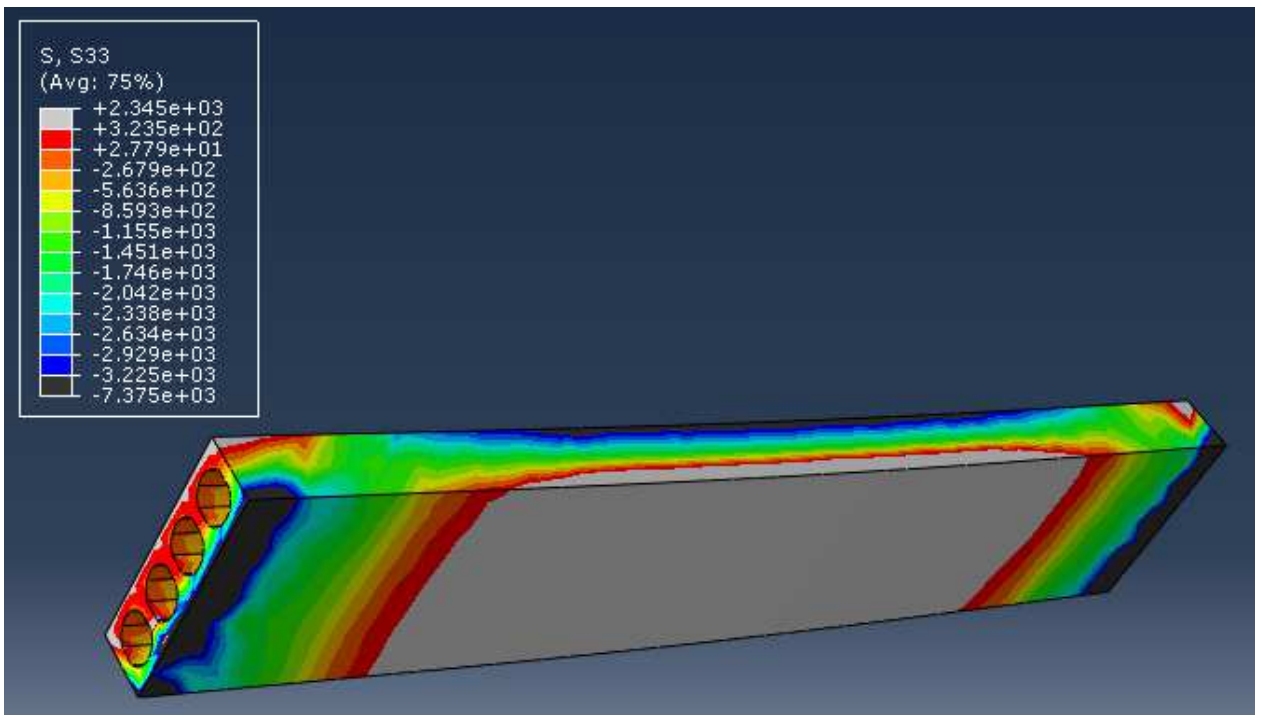

Fig. 18: Normal tension stress in concrete in the $S 370$ at the end of loading 
Table 2: Maximum displacement and maximum force

\begin{tabular}{llllr}
\hline Row & Model & Maximum displacement at linear range & Maximum displacement nonlinear range & Slab resistance \\
\hline 1 & S200 & 2.05 & 5.79 & 407.69 \\
2 & S265 & 2.21 & 5.83 & 808.10 \\
3 & S320C & 2.10 & 5.93 & 1572.26 \\
4 & S370 & 1.50 & 3.97 & 1502.73 \\
\hline
\end{tabular}

\section{Conclusion}

The main conclusions of the experimental work should be presented. The contribution of the work to the scientific community and its economic implications should be emphasized.

According to the results presented, the following can be expressed:

- Comparing the four-model nonlinear static loading diagrams, the S265 elasticity hardness is 2.5 times higher than the S200 model. The S320C's elastic hardness is about 1.33 times more than the S370. The S320C's elastic stiffness is about 3.8 times that of the S200

- By comparing the displacement graphs of all four models, the final shear strength of the S200 model was the lowest and the maximum shear strength of the S320C model was the lowest. The shear strength of the $\mathrm{S} 370$ is less than the $\mathrm{S} 320 \mathrm{C}$, due to the presence of non-circular polygon holes

- According to the comparison of tensile stresses and compression stresses in all four models, in all models in the tensile region, there is almost a tensile failure, but in the compression region S320 has a slight compression failure and the rest of the models have a compressive failure region as the same as experienced sample

\section{Acknowledgment}

This research is not financially supported. But, It is a time to appreciate Dr. Akbarpour for his supporting to prepare this research.

\section{Author's Contributions}

Reza Salehi: Performed modeling with FEM software and data analysis. Also, participated in writing the manuscript.

Abbas Akbarpour Nikghalb Rashti: Provided the research topic and guided the research development, experimental plan and data analysis. Also, participated in writing the manuscript.

\section{Ethics}

This article is an original research paper. There are no ethical issues that may arise after the publication of this manuscript.

\section{References}

ACI, 2005. Committee. building code requirements for structural concrete (ACI 318-05) and commentary. American Concrete Institute, Farmington Hills, MI.

CEN, 2011. Precast concrete products-hollow core slabs. EN 1168+A3, European Committee for Standardization.

Dimitrios, K., P. Fermín, R. Bruno, P. Lincy and J.M. Ndambi et al., 2013. Blast performance of reinforced concrete hollow core slabs in combination with fire: Numerical and experimental assessment. Fire Safety J., 57: 69-82. DOI: 10.1016/j.firesaf.2012.10.027

Brunesi, E. and R. Nascimbene, 2015. Numerical webshear strength assessment of precast prestressed hollow core slab units. Eng. Structures, 102: 13-30. DOI: 10.1016/j.engstruct.2015.08.013

Fallahi, M., M. Haghighfar, R. Madandoust and S.S. Roudsari, 2018. Modeling of reinforced concrete frames with Infill walls under cyclic loading Strengthening with CFRP. J. Eng. Applied Sci.

FIB, 2012. Model code 2010-final draft, vols. 1 and 2, federation internationale du béton, bulletins 65 and 66 . Fédération Internationale du Béton, Lausanne, Switzerland.

Hegger, J., T. Roggendorf and N. Kerkeni, 2009. Shear capacity of prestressed hollow core slabs in slim floor constructions. Eng. Structures, 31: 551-559. DOI: $10.1016 /$ j.engstruct.2008.10.006

Pisanty, A. and P.E. Regan, 1991. Direct assessment of the tensile strength of the web in prestressed precast hollow-core slabs. Mater. Structures, 24: 451-455. DOI: $10.1007 /$ BF02472017

Roudsari, S., S. Hamoush, S. Soleimani, T.A. Lebdeh and M. HaghighiFar, 2018. Analytical study of reinforced concrete beams strengthened by FRP bars subjected to impact loading conditions. Am. J. Eng. Applied Sci. DOI: 10.3844/ofsp.11916

Sayyar Roudsari, S., S.A. Hamoush and S.M. Soleimani, Rahmat Madandoudst, 2018. Evaluation of large-size reinforced concrete columns strengthened for axial load using fiber reinforced polymers. Engineering Structure.

Sgambi, L., K. Gkoumas and F. Bontempi, 2014. Genetic algorithm optimization of precast hollow core slabs. J. Browse, 13: 389-409. DOI: $10.12989 /$ cac.2014.13.3.389

Soleimani, M. and S.S. Roudsari. 2015. Analytical study of reinforced concrete beams tested under impact loading. Proceedings of the 4th International Workshop Performance, Protection and Strengthening Structures Under Extreme Loading, (UEL' 15), pp: 620-627. 